\title{
A raça Gir Mocha na região Nordeste do Brasil: estrutura genética populacional via análise de pedigree
}

\author{
[The Polled Gir Polled in Northeastern Brazil: population genetic structure via \\ analysis of pedigree] \\ L.M.S. Muniz ${ }^{1}$, L.A. Souza ${ }^{2}$, A.C.B. Barbosa ${ }^{3}$, D.P. Ambrosini ${ }^{1}$, A.P. Oliveira ${ }^{2}$, \\ P.L.S. Carneiro ${ }^{3}$, C.H.M. Malhado ${ }^{3,6}$, R. Martins Filho ${ }^{4}$, R.A.B. Duarte ${ }^{5}$ \\ ${ }^{1}$ Aluno(a) de pós-graduação - UESB - Itapetinga,BA \\ ${ }^{2}$ Aluna de pós-graduação - UESB - Jequié, BA \\ ${ }^{3}$ UESB - Jequié, BA \\ ${ }^{4}$ Visitante Sênior Nacional - Universidade Federal do Ceará - Cariri, CE \\ ${ }^{5}$ Aluno de pós-graduação - UFRB - Cruz das Almas, BA \\ ${ }^{6}$ Bolsista de produtividade do $\mathrm{CNPq}$
}

\begin{abstract}
RESUMO
Foram utilizados dados de pedigree de 2.558 bovinos da raça Gir Mocha nascidos no período de 1954 a 2005. As análises foram realizadas utilizando-se o programa Endog. Do total de animais estudados, $61,9 \% ; 10,6 \%$ e $0,1 \%$ possuíam pedigree na primeira, segunda e terceira gerações, respectivamente.O número efetivo de rebanhos que forneceram machos reprodutores foi de 10,25 para pais e 3,87 para avôs, confirmando a baixa integralidade do pedigree. O número de animais fundadores foi de 975,5, e o número efetivo de fundadores de 141,34. O número de ancestrais na população referência foi de 924 animas, dos quais apenas 39 explicaram $50 \%$ da variabilidade genética da população.O coeficiente médio de relação foi estimado em $0,75 \%$, sendo o maior coeficiente individual de $25 \%$. O coeficiente de endogamia foi igual a zero de 1954 a 1984. Vale salientar que, neste período, estão incluídos os animais sem ascendência conhecida. A endogamia e o coeficiente médio de relação da população foram baixos, contudo podem estar subestimados em razão da pequena integralidade do pedigree.
\end{abstract}

Palavras-chave: ancestrais, endogamia, fundadores, genealogia

\begin{abstract}
In this study we used data from the 2558 pedigree cattle polled Gir born from 1954 to 2005. Analyses were performed using the Endog program. Of all animals studied, $61.86 \%, 10.56 \%$ and $0.10 \%$ had a pedigree in the first, second and third generation, respectively. The effective number of herds that provide breeding males was 10.25 for parents and 3.87 for grandparents, corroborating the low completeness of the pedigree. The number of founder animals was 975.5 and the effective number of founders were 141.34. The number of ancestors in the reference population was 924 animals from which only 39 accounted for $50 \%$ of the genetic variability of the population. The average relationship coefficient was estimated at $0.75 \%$, the largest individual coefficient was $25 \%$. The inbreeding coefficient was zero from 1954 to 1894. It is noteworthy that during this period included the population was low, but may be underestimated because of the small pedigree integrity.
\end{abstract}

Keywords:ancestral, inbreeding, founder, genealogy

\section{INTRODUÇÃO}

A raça Gir foi, durante algum tempo, a raça zebuína mais numerosa e valorizada do Brasil.
Foi introduzida no país provavelmente por volta de 1906e corresponde à raça homônima na Índia (Santiago, 1986). Segundo Madalena (2002), em 1907, alguns exemplares da raça Gir importados

Recebido em 10 de junho de 2011 
seguiram para Goiás e, já em 1912, animais Gir com caráter mocho foram apresentados na Feira Agropecuária Oficial do Estado. Em 1976 foi instituído o livro de registro genealógico, incluindo a variedade mocha, e no triênio 1999/2000/2001, foi registrada a média de 514 animais (ABCZ, 2006).

Os dados de pedigree são extremamente relevantes na genética e no melhoramento animal, uma vez que são imprescindíveis na avaliação genética e em estudos de estrutura genética populacional. Recentemente, vários estudos foram realizados avaliando endogamia, tamanho efetivo da população, diversidade genética e outros importantes parâmetros populacionais (Clevelandet al., 2005; Parlandet al., 2007; Carolino e Gama, 2008; Malhadoet al., 2008 e Martínezet al., 2008). Segundo Reis Filhoet al. (2010), o uso massivo de um pequeno número de touros provados com alto valor genético pode afetar a longo prazo o ganho genético por meio da redução da variabilidade genética.

O tamanho efetivo da população é um parâmetro-chave no processo evolutivo e na genética quantitativa, pois fornece uma medida da taxa de oscilação genética e da consanguinidade de uma população. O coeficiente de endogamia depende do tamanho efetivo da população, e quanto menor for $\mathrm{o}$ tamanho da população, em gerações anteriores, maior será o número de ancestrais comuns e maior será o coeficiente de endogamia (Breda et al., 2004). Esses parâmetros populacionais, tamanho efetivo e coeficiente de endogamia são fundamentais para definir se há ou não situação de risco em uma população.

É importante salientar que o sucesso de programas de melhoramento genético é extremamente dependente do conhecimento dos vários fatores que podem interferir na seleção, como tamanho efetivo, intervalo de gerações e variabilidade genética (Malhado et al., 2008). O rebanho da raça Gir Mocha é relativamente pequeno, e estudos da sua estrutura genética populacional são escassos, especialmente na região Nordeste. Assim, o objetivo deste estudo consiste em avaliar a estrutura genética populacional, via análises de pedigree, verificando a relação da endogamia com o coeficiente médio de relação, descrevendo o tamanho efetivo e o intervalo de gerações, na raça Gir Mocha no Nordeste do Brasil.

\section{MATERIAL E MÉTODOS}

Os dados utilizados referem-se às informações de pedigree de bovinos da raça Gir Mocha, criados na região Nordeste do Brasil, nascidos no período de 1954 a 2005. O banco de dados foi proveniente do controle de desenvolvimento ponderal da Associação Brasileira de Criadores de Zebu (ABCZ).

O programa Endog(GutiérrezeGoyache, 2005) foi utilizado para análise do pedigree e estimação dos parâmetros baseados na probabilidade de origem do gene, coeficiente médio de endogamia, coeficiente de parentesco, tamanho efetivo da população e intervalo de gerações. Todos os arquivos foram montados, e as análises estatísticas feitas no programa computacional SAS (Statistical..., 2003).

Para estimação de parâmetros baseados na probabilidade de origem do gene, foi calculado o número efetivo de fundadores e o número efetivo de ancestrais. O número efetivo de fundadores representa o número de animais com igual contribuição que produziriam a mesma variabilidade genética encontrada na população estudada. A aproximação clássica na determinação do número efetivo de fundadores foi dada por:

$\mathrm{f}_{\mathrm{e}}=\frac{1}{\sum_{\mathrm{k}=1}^{\mathrm{f}} \mathrm{q}_{\mathrm{k}}^{2}}$, em que:

$f_{\mathrm{e}}=$ número efetivo de fundadores;

$\mathrm{q}_{\mathrm{k}}=$ probabilidade de o gene ser originado do fundador $k$

O número efetivo de ancestrais representa o número mínimo de animais (fundadores ou não) necessários para se explicar a total diversidade genética da população estudada. A determinação do número efetivo de ancestrais foi realizada computando-se a contribuição marginal de cada ancestral por:

$\mathrm{f}_{\mathrm{a}}=\frac{1}{\sum_{\mathrm{j}=1}^{\mathrm{a}} \mathrm{q}_{\mathrm{j}}^{2}}$, em que:

$f_{\mathrm{a}}=$ número efetivo de ancestrais;

$\mathrm{q}_{\mathrm{j}}=$ contribuição marginal de um ancestral $j$ (não

necessariamente fundador), ou seja, a 
contribuição genética de ancestral que não é explicada por um ancestral escolhido anteriormente.

Para o cálculo do coeficiente de endogamia $(F)$, utilizou-se o algoritmo proposto por Meuwissen e Luo(1992).O coeficiente médio de relação (CR) ou average relatedness coefficient $(A R)$ calcula simultaneamente a consanguinidade e coancestralidade individual Gutiérrez et al. (2003). Esse parâmetro foi calculado utilizandose um algoritmo para obter um vetor c' definido como:

$\mathrm{c}^{\prime}=(1 / \mathrm{n}) 1^{\prime} \mathrm{A} \quad$ [1], em que:

A é o numerador da matriz de parentesco de tamanho $\mathrm{n} \times \mathrm{n}$.

Por outro lado, o numerador da matriz de parentesco pode ser obtido da matriz $P$,em que:Pijé igual a 1 se $j$ é pai de $i$,e 0 caso não seja, o que define os pais dos animais (Quaas, 1976), por meio de:

$A=(I-1 / 2 P)-1 D\left(I-1 / 2 P^{\prime}\right)-1 \quad$ [2], em que: I é a matriz identidade e $\mathrm{D}$ é uma matriz diagonal com elementos não zero obtidos por:

dii = $1-1 / 4$ ajj - 1/4 akk;

dii $=1$, se nenhum dos pais é conhecido; dii $=3 / 4$, se um dos pais é conhecido; dii= $1 / 2$, se ambos os pais são conhecidos; j e k são os pais do indivíduo $\mathrm{i}$.

A partir de [2], A (I - 1/2 $\left.\mathrm{P}^{\prime}\right)=(\mathrm{I}-1 / 2 \mathrm{P})-1 \mathrm{D}$ [3]. Pré-multiplicando ambos os lados de [3]por $(1 / \mathrm{n})$ 1', obtém-se:

$(1 / n) 1^{\prime} \mathrm{A}\left(\mathrm{I}-1 / 2 \mathrm{P}^{\prime}\right)=(1 / \mathrm{n}) 1^{\prime}(\mathrm{I}-1 / 2 \mathrm{P})-1 \mathrm{D}$.

E usando [1]: $c^{\prime}\left(I-1 / 2 P^{\prime}\right)=(1 / n) 1^{\prime}(I-1 / 2 P)-1 D$, multiplicando c' entre parênteses e isolando c': $c^{\prime}=(1 / n) 1^{\prime}\left(I-1 / 2\right.$ P) -1 D + 1/2 $c^{\prime} P^{\prime}$ [4].

O número equivalente de gerações, por sua vez, foi obtido pelo somatório dos termos $(1 / 2)^{\mathrm{n}}$ de todos os ancestrais conhecidos, em que n é o número de gerações que separa o indivíduo de cada ancestral conhecido (Maignelet al., 1996).

Os principais fundadores e/ou ancestrais foram ordenados de maneira decrescente,com base nos seus valores de CR e contribuição, respectivamente, pelo procedimento SORT do SAS (Statistical..., 2003). Para fins de comparação da classificação dos animais, em relação ao CR e à contribuição, foi efetuada uma análise de correlação de classificação ou ordem, utilizando-se a correlação de Spearman do PROC CORR do SAS (Statistical..., 2003).
O intervalo médio de gerações foi estimado a partir dos passos: pai-filho, pai-filha, mãe-filho e mãe-filha, de acordo com a fórmula:

$\mathrm{L}=1 / 4(\mathrm{LPM}+\mathrm{LPF}+\mathrm{LMM}+\mathrm{LMF})$, em que:

$\mathrm{LPM}=$ intervalo médio entre pais e filhos; LPF = intervalo médio entre pais e filhas; LMM = intervalo médio entre mães e filhos; LMF = intervalo médio entre mães e filhas.

Com o intuito de averiguar o nível de endogamia e a estrutura populacional, as estatísticas F de Wright (1965) Fit, Fst e Fis foram calculadas. O coeficiente Fit, que expressa a taxa média de endogamia, foi estimado por meio da aplicação de um programa em linguagem Fortran, que utiliza o algoritmo descrito por Meuwissen e Luo(1992). O Fst designa o coeficiente médio de endogamia esperado se os reprodutores de cada período fossem acasalados aleatoriamente. $\mathrm{O}$ coeficiente Fis expressa o desvio da casualidade obtida nos acasalamentos atuais e foi obtido como $(1-$ Fit $)=(1$ - Fst $)(1$ - Fis $)$. Se Fis $>0$, então a endogamia atual (Fit) ultrapassa o nível esperado sob acasalamentos ao acaso (Fst), implicando que os acasalamentos estejam acontecendo entre animais mais aparentados que a média. Nesta hipótese, consequentemente, a população estará dividida em subpopulações. Quando Fis $<0$, evita-se a endogamia, ou seja, o acasalamento entre subpopulações é predominante.

O tamanho efetivo da população (Ne) foi estimado por meio da taxa de variação dos coeficientes médios de endogamia entre gerações sucessivas, conforme equação a seguir:

$\Delta F=\frac{F_{t}-F_{t-1}}{1-F_{t-1}}, \quad$ com rearranjos $N_{e}=\frac{1}{2 \Delta F}$, em que: $F_{t}=$ coeficiente médio de endogamia estimado na geração atual; $\mathrm{F}_{\mathrm{t}-1}=$ coeficiente médio de endogamia estimado na geração anterior.

\section{RESULTADOS E DISCUSSÃO}

Nas primeiras décadas de 1954 a 1970, o rebanho era muito pequeno, com poucos exemplares da raça (Fig. 1). A partir de 1972, houve aumento expressivo do número de animais, e entre 1976 e 1998, houve períodos intercalados de ascensão e declínio do número de animais. No ano de 1989, verificou-se o máximo de nascimento na raça, chegando a quase 250 animais registrados na região Nordeste. 


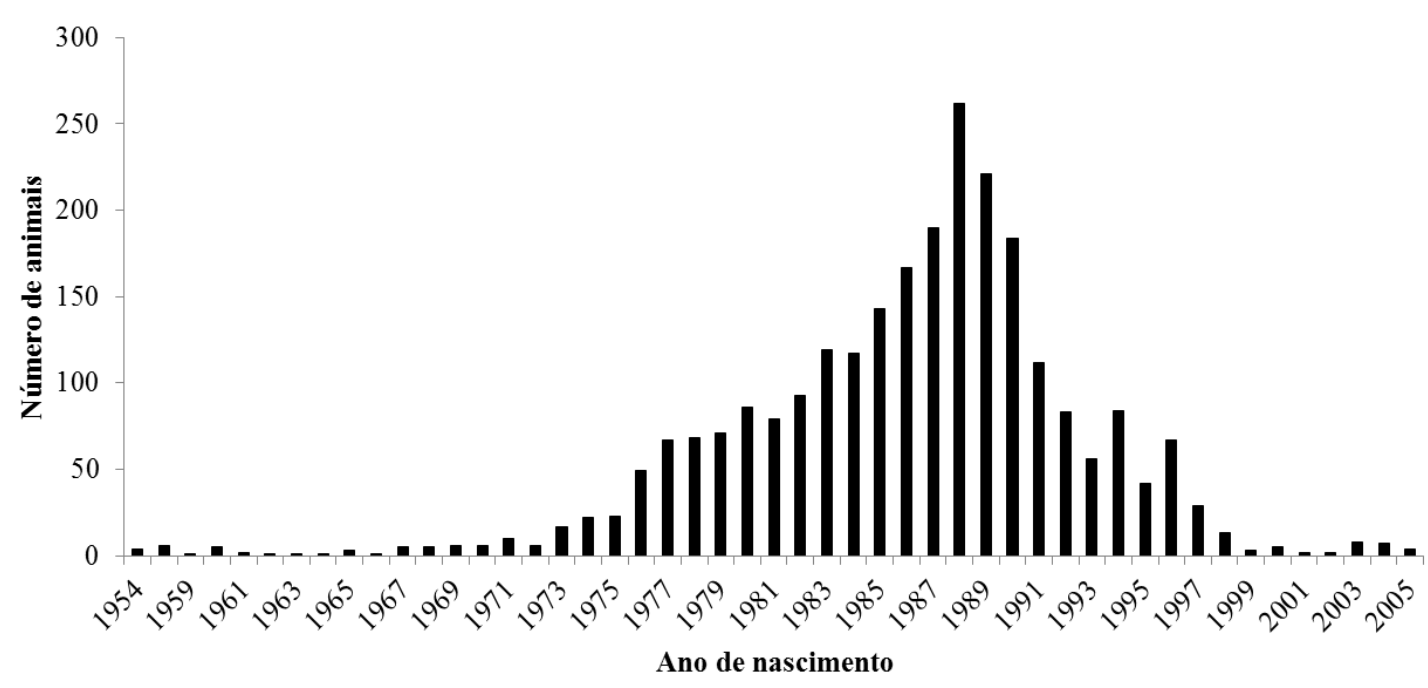

Figura 1. Número de animais nascidos da raça Gir Mocha na região Nordeste do Brasil, no período de 1954 a 2005.

Observou-se pequeno aumento do tamanho efetivo (Ne) nos períodos 1964-1971 e 19681975, mas o pico do $\mathrm{Ne}$ ocorreu nos períodos 1974-1981 e 1976-1985 (Fig. 2), em que atingiu o maior valor (120). A partir deste período, o Ne caiu até o último período avaliado, atingindo o valor de 20 animais. Este valor é extremamente pequeno e menor, inclusive, que o $\mathrm{Ne}$ de muitos rebanhos de animais que estão sob conservação. O decréscimo no número de animais com registro de nascimentos nos últimos anos, aliado à diminuição do $\mathrm{Ne}$ e à perda da variabilidade genética, compromete o uso desta raça nos sistemas de produção e exige medidas para ampliação da raça. Farias et al. (2006) também salientaram para a raça Gir Mocha do Brasil que o aumento na endogamia, a diminuição no tamanho efetivo, juntamente com a diminuição nos parâmetros de probabilidade de origem do gene, indicam claramente perda de variabilidade genética na população estudada.

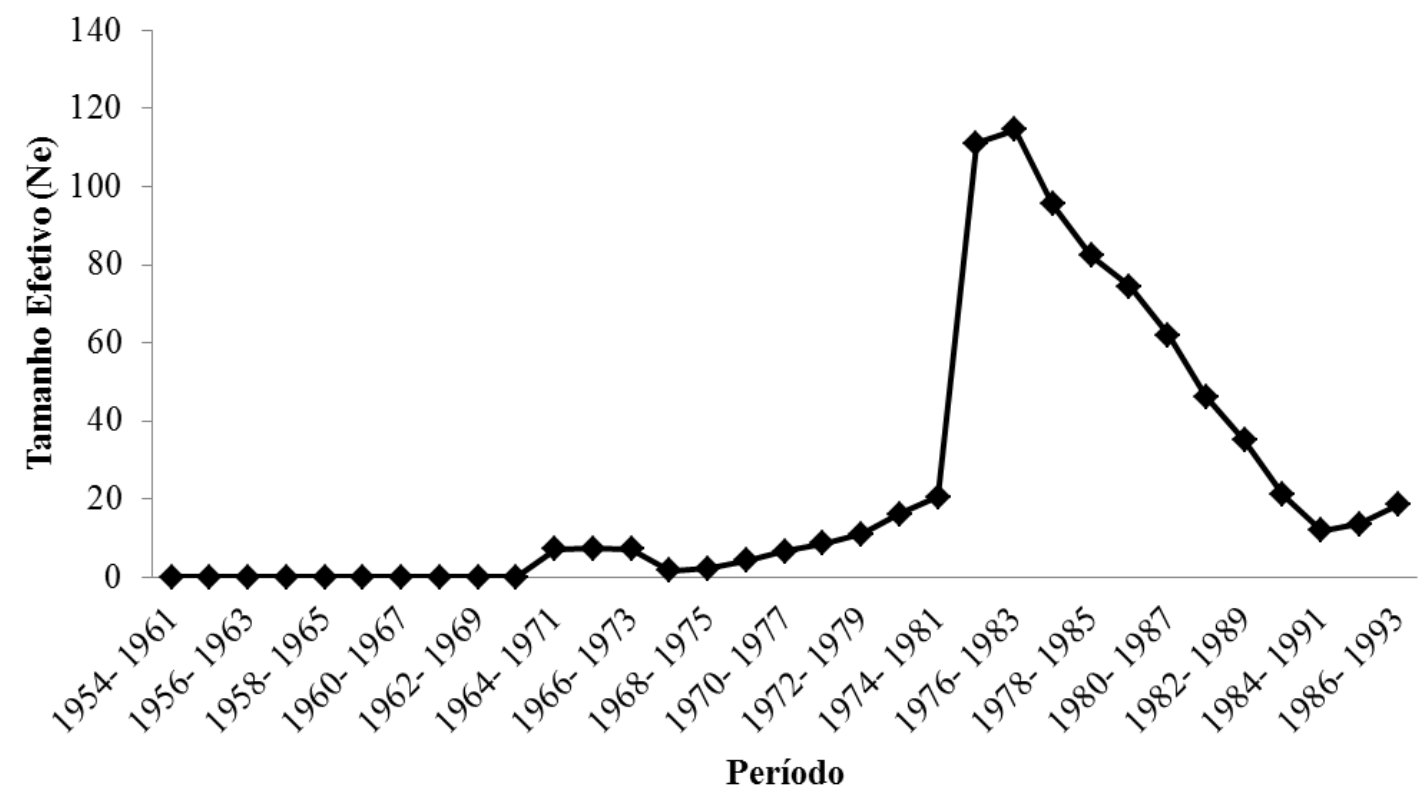

Figura 2. Tamanho efetivo no período de 1954 a 1993, em bovinos da raça Gir Mocha do Nordeste brasileiro. 
Valor muito baixo de tamanho efetivo foi observado por Faria et al. (2001), que avaliaram parâmetros populacionais do rebanho Sindi do Brasil e encontraram tamanho efetivo de 19 no último período avaliado (1994-1998), concluindo que o rebanho Sindi apresenta sério risco de desaparecimento no Brasil.

Madalena et al. (2002), ao avaliarem o tamanho efetivo por períodos de bovinos da raça Gir Mocha, no Brasil, entre os anos de 1976 a 1998, indicaram grande queda no último período, representando cerca de $10 \%$ do que se obteve no início do estudo. Os autores sugeriram, um Ne mínimo de 40 por geração, para maximizar o retorno econômico em população selecionada com estrutura de inseminação artificial.

Carneiro et al. (2007) afirmaram que, ao se utilizarem populações com pequenos tamanhos efetivos para seleção, os resultados podem ser influenciados pela oscilação genética e podem resultar em grandes variações nos ganhos genéticos.

O intervalo médio de gerações é fundamental em um programa de seleção, pois intervalos grandes diminuem o ganho genético anual para a característica objetivo da seleção, o que reduz o retorno econômico do programa. Intervalos de geração muito menores são possíveis de serem alcançados segundo Carneiro et al. (2009).

As estimativas do intervalo de gerações para as quatro passagens gaméticas, para todo o pedigree dos bovinos Gir Mocha, foram: 6,75 $\pm 1,042$ (paifilho), 7,97 $\pm 0,3151$ (pai-filha), 7,12 $\pm 0,699$ (mãefilho), 8,94 $\pm 0,4428$ (mãe-filha), com intervalo médio de 7,54 $\pm 0,6247$ anos. Faria et al. (2001), com os dados da raça Gir Mocha registrados no Brasil, encontraram resultados para a média do intervalo de geração de 6,71 anos.

Dos 2.558 animais estudados, 61,9\%; 10,6\% e $0,10 \%$ possuíam pedigree na primeira, segunda e terceira ascendências, respectivamente (Fig.3). É importante destacar a grande perda de informações de pedigree da primeira para a segunda geração, visto que, em média, $38,1 \%$ dos animais não possuíam pai e mãe conhecidos e $89,4 \%$ não possuíam avós no pedigree. Corroborando estas informações, o número efetivo de rebanhos que forneceram machos reprodutores foi de 10,25 para pais e de apenas 3,87 para avôs. As estimativas dos parâmetros populacionais são baseadas no pedigree, sendo assim, quanto maior sua integralidade, mais precisos serão os parâmetros.

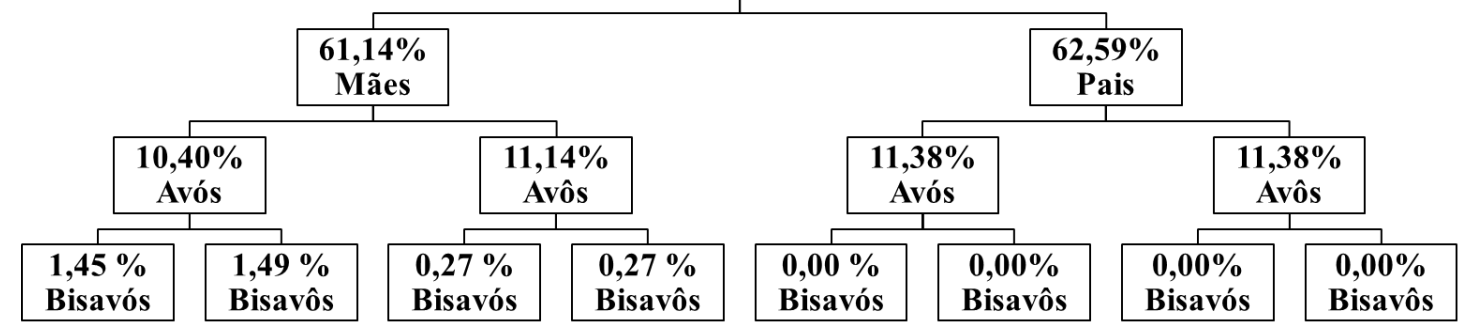

Figura 3. Estrutura do pedigree de bovinos da raça Gir Mocha no Nordeste do Brasil.

O número médio de gerações máximas, o incremento de endogamia e o número efetivo de animais foram 0,$86 ; 0,64 \%$ e 77,93, respectivamente. Já para gerações equivalentes, os valores foram 0,$73 ; 0,90 \%$ e 72,5 respectivamente. Observa-se que o número de gerações equivalentes é menor que o número de gerações máximas, em razão da baixa integralidade do pedigree.
O número real de rebanhos fundadores foi 66 , e o número efetivo de rebanhos fundadores de apenas 11,6. Os animais fundadores com pais desconhecidos foram de 999, e, considerando-se animais com apenas um pai desconhecido, ou seja, meio-fundador, foi de 975,5 (Tab. 1). Estas informações indicam que reprodutores de poucos rebanhos têm sido utilizados intensivamente, contribuindo para diminuição do $\mathrm{Ne}$ e aumento 
da endogamia na população. O número efetivo de animais fundadores na população referência foi de 1559. O número efetivo de ancestrais $\left(f_{\mathrm{a}}\right)$ foi equivalente a 60 , dos quais 39 animais explicaram $50 \%$ da variabilidade genética da população. Malhado et al. (2010), ao estudarem o histórico da raça Gir registrada no Nordeste brasileiro, observaram 5.945 animais na população referência, em que ambos os pais são conhecidos, enquanto 2.952 animais tiveram um ou ambos os pais desconhecidos. O número efetivo de fundadores foi de 260 , e o aumento da endogamia causada pela contribuição dos fundadores foi de $0,09 \%$. A maior contribuição genética dos 10, 30 e 171 ancestrais influentes (fundadores ou não) explicou 14,9; 26,8 e 50\% da variabilidade genética de toda a população. Já Reis Filho (2006), ao estudar a raça Gir Leiteiro no Brasil, observou número efetivo de fundadores de 146 e esperado aumento da endogamia de $0,34 \%$. Além disso, relatou que apenas 28 fundadores foram responsáveis por $50 \%$ dos genes da população. Salientou que o rebanho do Gir Leiteiro no Brasil é representado apenas por uma parte da população, ou seja, vários ancestrais e fundadores da raça Gir Leiteiro não contribuíram para a formação da raça.

Tabela 1. Parâmetros populacionais do rebanho Gir Mocha no Nordeste do Brasil

\begin{tabular}{lc}
\hline Total de animais estudados & 2558 \\
\hline Número real de rebanhos fundadores & 66 \\
Número efetivo de rebanhos fundadores & 11,6 \\
Número (efetivo) de rebanhos que produzem pais & 10,25 \\
Número (efetivo) de rebanhos que produzem avós & 3,87 \\
Número equivalente de animais fundadores (um pai desconhecido = fundador médio) & 975,5 \\
Número de animais fundadores com os pais desconhecidos & 999 \\
Número efetivo de animais fundadores & 141,3 \\
Número de animais na população de referência & 1559 \\
Número de ancestrais na população de referência & 924 \\
Número efetivo de ancestrais & 60 \\
Número de ancestrais que explicam 50\% da variabilidade & 39 \\
\hline
\end{tabular}

O número efetivo de fundadores e de ancestrais verificados para a raça Gir Mocha foi próximo aos valores encontrados em estudos sobre a estrutura populacional de zebuínos, de112 e 78 na raça Tabapuã por Vercesi Filho et al. (2002) e de 87 e 60 na raça Nelore por Vozzi et al. (2006), respectivamente. Baixos valores de número efetivo de fundadores e ancestrais, quando comparados com os números das populações base e referência, fazem com que o rebanho se desenvolva a partir de estreita base genética, levando a um gargalo genético com perdas de genes de origem (Barros, 2009).

O fundador de maior importância para o rebanho foi o macho 1253279, com coeficiente de relação médio (CR) de 5,2\% (Tab. 2). Apenas uma fêmea (645255) foi encontrada entre os 10 principais fundadores. Dos 10 principais animais identificados como fundadores, oito também foram classificados como ancestrais. Esta associação foi verificada por meio da correlação de Spearman. A correlação de Spearman entre a classificação dos 39 animais fundadores, pelo CR, e ancestrais, pela contribuição, foi de $95,4 \%$ $(\mathrm{P}<0,01)$, indicando que a maior parte dos fundadores também são ancestrais, o que demonstra um pequeno efeito gargalo. $\mathrm{O}$ ancestral de maior relevância foi o macho 1253279 , responsável por $8,3 \%$ da variabilidade genética da população.

O coeficiente de relação médio (CR) populacional foi estimado em $0,75 \%$, sendo que o maior coeficiente individual foi de $25 \%$. O CR apresentou-se relativamente estável no período de 1954 a 1984, com valores anuais inferiores a $0,1 \%$ (Fig. 4). Esses resultados demonstram que não há animais sendo utilizados intensivamente neste período. 
Tabela 2. Descrição dos 10 principais fundadores e ancestrais (fundadores ou não) que explicam a variabilidade genética da população da raça Gir Mocha

\begin{tabular}{|c|c|c|c|c|c|c|}
\hline Fundador & Pai & Mãe & Sexo & $\begin{array}{c}\text { Ano de } \\
\text { nascimento }\end{array}$ & $\begin{array}{l}\text { CR } \\
(\%)\end{array}$ & $\begin{array}{l}\mathrm{N}^{\circ} \text { de filhos / } \\
\text { reprodutor }\end{array}$ \\
\hline 1253279 & & & $\mathrm{M}$ & 1974 & 5,25 & 170 \\
\hline 361983 & & & M & 1984 & 2,8 & 126 \\
\hline 1569804 & & & M & 1983 & 2,77 & 128 \\
\hline 377810 & & & M & 1988 & 2,72 & 133 \\
\hline 1591111 & & & M & 1978 & 1,46 & 69 \\
\hline 577969 & & & M & 1981 & 1,45 & 57 \\
\hline 1632616 & & & M & 1981 & 1,4 & 69 \\
\hline 580572 & & & M & 1976 & 1,1 & 18 \\
\hline 2121241 & & & M & 1971 & 0,96 & 33 \\
\hline 645255 & & & $\mathrm{~F}$ & 1974 & 0,93 & 1 \\
\hline Ancestral & & & \multicolumn{4}{|c|}{ Contribuição } \\
\hline 1253279 & & & $\mathrm{M}$ & 1974 & 8,26 & 170 \\
\hline 361983 & & & M & 1984 & 4,51 & 126 \\
\hline 1569804 & & & M & 1983 & 4,47 & 128 \\
\hline 377810 & & & M & 1988 & 4,36 & 133 \\
\hline 577969 & & & M & 1981 & 2,29 & 57 \\
\hline 1591111 & & & M & 1978 & 2,28 & 69 \\
\hline 1632616 & & & M & 1981 & 2,24 & 69 \\
\hline 405558 & 580572 & 283793 & M & 1982 & 1,8 & 58 \\
\hline 2121241 & & & M & 1971 & 1,48 & 33 \\
\hline 645255 & & & $\mathrm{~F}$ & 1974 & 1,35 & 1 \\
\hline
\end{tabular}

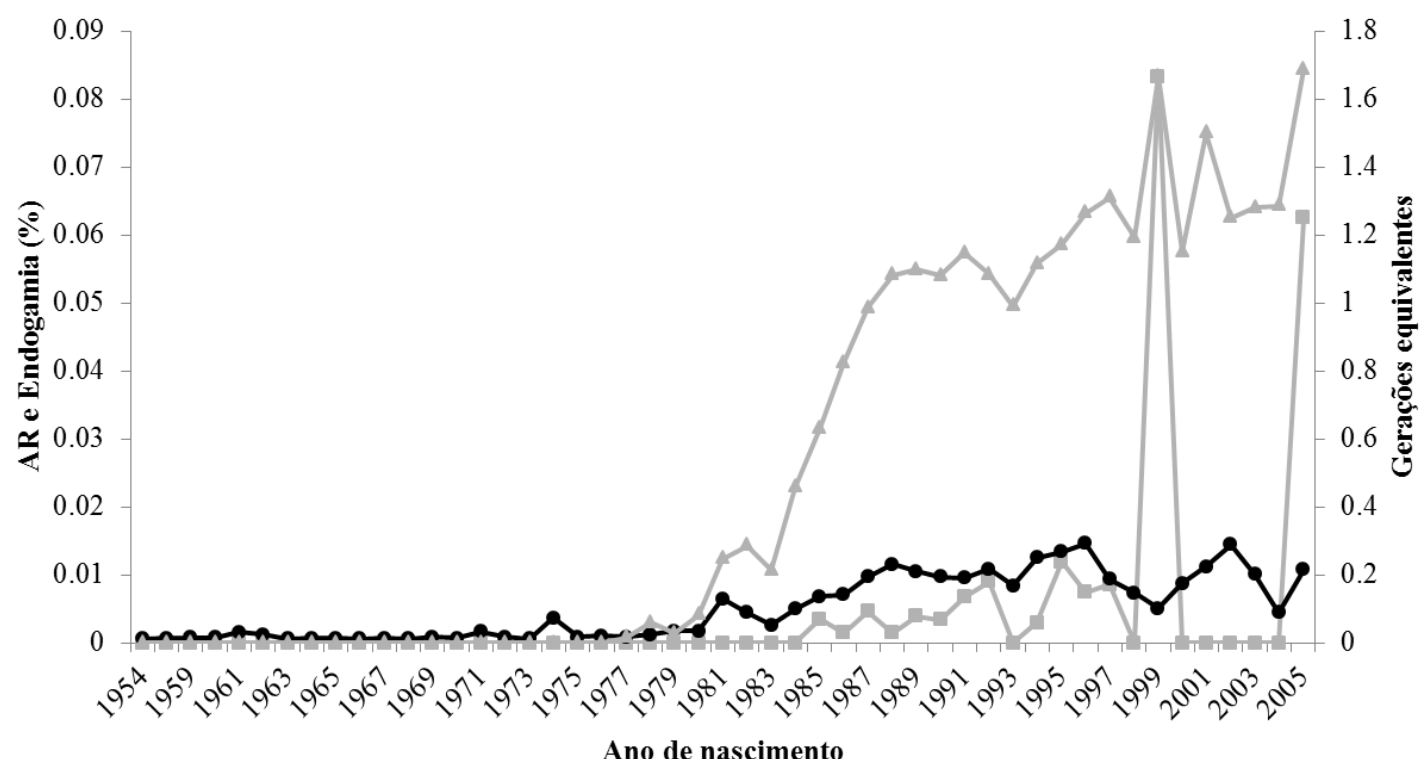

Figura 4. Variação da endogamia (quadrados) e coeficiente médio de parentesco (círculos), ambos em porcentagem, e valores médios de gerações equivalentes (triângulos) em bovinos da raça Gir Mocha no Nordeste do Brasil.

O coeficiente de endogamia $(\mathrm{F})$ foi igual a zero de 1954 a 1984 , e entre os anos de 1985 a 1997, foram encontrados valores de $\mathrm{F}$ inferiores a $1 \%$ (Fig. 4). Vale salientar que, neste período, estão incluídos animais sem ascendência conhecida, o que pode fazer com que esta estimativa possa estar subestimada. O coeficiente de endogamia de um indivíduo depende do conhecimento de 
sua ascendência. Sendo assim, quanto mais se conhece a ascendência de um individuo, mais confiável será o seu coeficiente de endogamia estimado em relação à base populacional definida.

O baixo valor de Fst indica a ausência de estruturação da população, e este fato pode ser observado na Tab. 3 (classificação dos rebanhos), em que é possível constatar que todos os rebanhos utilizam touros externos e que $57,5 \%$ deles vendem touros. A maioria dos rebanhos $(57,5 \%)$ foi classificada como multiplicadora - utiliza reprodutores externos ou próprios e vende reprodutores - e 42,5\% foram classificados como comerciais - utilizam reprodutores externos ou próprios e não vendem reprodutores. Apesar de ter sido constatado grande fluxo de genes entre os rebanhos (FST= 0,038 ), existe uma preocupação com a utilização de reprodutores próprios nos rebanhos multiplicadores e comerciais (em torno de 85\%), visto que a maioria desses animais não são avaliados. Resultados semelhantes foram encontrados por Reis Filho et al. (2010), ao avaliarem a estrutura populacional do Gir Leiteiro.

Tabela 3. Classificação dos rebanhos registrados dos bovinos Gir Mocha do Nordeste do Brasil, de acordo com a origem e o uso dos touros

\begin{tabular}{lccccc} 
Tipo de rebanho & $\begin{array}{c}\text { Utilizam touros } \\
\text { externos }\end{array}$ & $\begin{array}{c}\text { Utilizam touros } \\
\text { próprios }\end{array}$ & $\begin{array}{c}\text { Vendem } \\
\text { touros }\end{array}$ & $\begin{array}{c}\text { Número de } \\
\text { rebanhos }\end{array}$ & $\begin{array}{c}\text { Porcentagem } \\
\text { touros externos }\end{array}$ \\
\hline Núcleo & não & $\operatorname{sim}$ & $\operatorname{sim}$ & 0 & $0 \%$ \\
Multiplicador & $\operatorname{sim}$ & $\operatorname{sim}$ & $\operatorname{sim}$ & 22 & $57 \%$ \\
Multiplicador & $\operatorname{sim}$ & não & $\operatorname{sim}$ & 1 & $100 \%$ \\
Comercial & $\operatorname{sim}$ & $\operatorname{sim}$ & não & 12 & $67 \%$ \\
Comercial & $\operatorname{sim}$ & não & não & 5 & $100 \%$ \\
Isolado & não & sim & não & 0 & $0 \%$ \\
\hline
\end{tabular}

\section{CONCLUSÕES}

O intervalo médio de gerações foi alto, o que pode acarretar diminuição do ganho genético anual. O tamanho efetivo da população encontrase menor que os apresentados por muitos rebanhos de conservação, fato que sugere a necessidade de medidas de conservação e expansão dos rebanhos deste importante grupo genético. A endogamia e o coeficiente médio da população foram baixos, contudo podem estar subestimados em razão da pouca integralidade do pedigree.

\section{AGRADECIMENTO}

Ao $\mathrm{CNPq}$, pela bolsa de pesquisa concedida aos professores Carlos Henrique Mendes Malhado e Paulo Luiz Souza Carneiro; à Associação Brasileira de Criadores de Zebu, pelo acesso aos seus dados, e à UESB, CAPES e FAPESB, pelo apoio financeiro.

\section{REFERÊNCIAS}

ABCZ- Associação Brasileira dos Criadores de Zebu. Estatísticas 2006. Disponível em: http://www.abcz.org.br. Acessado em: 28 de Abril de 2007.

BARROS, E.A. Estrutura populacional e variabilidade genética do núcleo de conservação da raça Marota no Piauí. 63f. (Mestrado em Zootecnia. Universidade Federal Rural de Pernambuco, Recife, 2009.

BREDA, F.C.; EUCLYDES, R.F.; PEREIRA, R.A.T. et al. Endogamia e limite de seleção em populações selecionadas obtidas por simulação. Rev. Bras. Zootec., v.33, p.2017-2025, 2004.

CARNEIRO, P.L.S.; MALHADO, C.H.M.; EUCLIDES, R.F. et al. Oscilação genética em populações submetidas a métodos de seleção tradicionais e associados a marcadores moleculares. Rev. Bras. Zootec., v.35, p.84-91, 2007. 
CARNEIRO, P.L.S.; MALHADO, C.H.M.; MARTINS FILHO, R. et al. A raça Indubrasil no Nordeste brasileiro: melhoramento e estrutura populacional. Rev. Bras. Zootec., v.38, p.23272334, 2009.

CAROLINO, N.; GAMA, L.T. Indicators of genetic erosion in an endangered population: The Alentejana cattle breed in Portugal. J. Anim. Sci., v.86, p.47-56, 2008

CLEVELAND, M.A.; BLACKBURN, H.D.; ENNS, R.M. et al. Changes in inbreeding of US Herefords during the twentieth century. J. Anim. Sci., v.83, p.992-1001, 2005.

GUTIÉRREZ, J.P.; ALTARRIBA, J.; DÍAZ, C. et al. Pedigree analysis of eight Spanish beef cattle breeds. Gen. Select. Evol., v.35, p.43-64, 2003 .

GUTIÉRREZ, J.P.; GOYACHE, F. A note on ENDOG: a computer program for monitoring genetic variability of populations using pedigree information. J. Anim. Breed. Genet., v.122, p.172-176, 2005.

FARIA, F.J.C.; MADALENA, F.E.; JOSAHKIAN, L.A. Parâmetros populacionais do rebanho Gir Mocho registrado no Brasil. Rev. Bras. Zootec., v.30, p.1984-1988, 2001.

FARIA, F.J.C.; VERCESI, A.E.F.; MADALENA, F.E.; JOSAHKIAN, L.A. Estrutura Genética da Raça Gir Mocha Registrada no Brasil. B. Ind. Anim., v.63, p.135-141, 2006.

MAIGNEL, L.; BOICHARD, D.; VERRIER, E. Genetic variability of French dairy breeds estimated from pedigree information. Interbull Bull, v.14, p.49-54, 1996.

MADALENA, F.E.; FARIA, F.J.C.; VERCESI A.E.F.; JOSAHKIAN, L.A. Endogamia e tamanho efetivo populacional na raça Gir Mocho. Anais: SIMPÓSIO NACIONAL DE MELHORAMENTO ANIMAL. 4., 2002. João Pessoa, PB. 3p.

MALHADO, C.H.M.; CARNEIRO, P.L.S.; PEREIRA, D.G.; MARTINS FILHO, R. Progresso genético e estrutura populacional do rebanho Nelore no Estado da Bahia. Pesq. Agrop. Bras., v.43, p.1163-1169, 2008.
MALHADO, C.H.M.; CARNEIRO, P.L.S.; MALHADO, A.C.M. et al. History of registered Gyr breed in Brazilian Northeast: population structure and genetic improvement of growth traits. Cienc. Rural, v.40, p.1385-1391, 2010.

MARTÍNEZ, R.A.; GARCÍA, D.; GALLEGO, J.L. et al. Genetic variability in Colombian Creole cattle populations estimated by pedigree information. J. Anim. Sci., v.86, p.545-552, 2008.

MEUWISSEN, T.H.E.; LUO, Z. Computing inbreeding coefficients in large populations. Gen. Selec. Evol., v.24, p.305-313, 1992.

PARLAND, S.Mc.; KEARNEY, J.F.; RATH, M. et al. Inbreeding trends and pedigree analysis of Irish dairy and beef cattle populations. J. Anim. Sci., v.85, p.322-331, 2007.

QUAAS, R.L. Computing the diagonal elements and inverse of a large numerator relationship matrix. Biometrics, v.32, p.949-953, 1976.

REIS FILHO, J.C. Endogamia na raça Gir. 2006. 50f. Dissertação (Mestrado em Genética e Melhoramento Animal) - Universidade Federal de Viçosa, Viçosa, MG.

REIS FILHO, J.C.; LOPES, P.S.; VERNEQUE, R.S. et al. Estrutura populacional de Bovinos leiteiros da raça Gir no Brasil. Rev. Bras. Zootec., v.39, p.2640-2645, 2010.

SANTIAGO, A.A. O Zebu na Índia, no Brasil e no Mundo. Campinas: Instituto Campineiro de Ensino Agrícola, 1986. 745p.

STATISTICAL analysis systems user's guideSAS: Version 9.1. Cary: SAS Institute, 2003.

VERCESI FILHO, A.E.; FARIA, F.J.C.; MADALENA, F.E. et al. Estrutura populacional do rebanho Tabapuã registrado no Brasil. Arq. Bras. Med. Vet. Zootec., v.54,p.609-617, 2002.

VOZZI, P.A.; MARCONDES, C.R.; MAGNABOSCO, C.U. et al. Structure and genetic variability in Nellore (Bosindicus) cattle by pedigree analysis. Gen. Molec. Biol., v.29, p.482-485, 2006.

WRIGHT, S. The interpretation of population structure by F-statistics with special regards to systems of mating. Evolution, v.9, p.395-420, 1965. 